\title{
Quantificação de serapilheira e de nutrientes em uma \\ Floresta Ombrófila Densa
}

\section{Quantification of litter and nutrients on an Atlantic Rain Forest}

\author{
Marcos Vinicius Winckler Caldeira ${ }^{1 *}$; Marcelo Diniz Vitorino²; \\ Suélen Schramm Schaadt ${ }^{3}$; Eclair Moraes ${ }^{3}$; Rafaelo Balbinot ${ }^{4}$
}

\section{Resumo}

Seja qual for o tipo de floresta, a produção de serapilheira representa o primeiro estágio de transferência de nutrientes e energia da vegetação para o solo, pois a maior parte dos nutrientes absorvidos pelas plantas retorna ao piso florestal através da queda de serapilheira ou lavagem foliar. O objetivo desse estudo foi quantificar a produção de serapilheira acumulada e o conteúdo de nutrientes em três estádios sucessionais da Floresta Ombrófila Densa Submontana, Blumenau/SC. Para as coletas da serapilheira acumulada foram utilizadas cinco unidades amostrais (UAs) retangulares de $10 \mathrm{~m}$ x $20 \mathrm{~m}$ em cada estádio sucessional, totalizando 15 UAs. Em cada UA com o auxílio de um gabarito de metal de $0,25 \mathrm{~m}$ x $0,25 \mathrm{~m}$ foram realizadas as coletas do material de estudo de forma aleatória com cinco repetições por UA a cada 30 dias (75 amostras/mês, ou seja, 25 amostras/estádio sucessional). Em ordem decrescente, a produção média de serapilheira acumulada nos vinte e dois meses de coleta ocorreu no estádio III (5,28 Mg ha $\left.{ }^{-1}\right)>$ estádio II (5,02 $\left.\mathrm{Mg} \mathrm{ha}^{-1}\right)>$ estádio I $\left(4,47 \mathrm{Mg} \mathrm{ha}^{-1}\right)$. O conteúdo total de macronutrientes na serapilheira acumulada em ordem decrescente no estádio sucessional I e II foram: $\mathrm{N}>\mathrm{Ca}>\mathrm{Mg}>\mathrm{K}>\mathrm{S}>\mathrm{P}$, e no estádio sucessional III: $\mathrm{N}>\mathrm{Ca}$ $>\mathrm{Mg}>\mathrm{S}>\mathrm{K}>\mathrm{P}$. A floresta em estudo apresentou para o conteúdo total de micronutrientes na serapilheira acumulada nos três estádios sucessionais a seguinte ordem decrescente: $\mathrm{Fe}>\mathrm{Mn}>\mathrm{Zn}>\mathrm{B}>\mathrm{Cu}$. No que se refere ao conteúdo total de carbono orgânico na serapilheira acumulada, a seqüência foi: estádio sucessional II $\left(1,65 \mathrm{Mg} \mathrm{ha}^{-1}\right)>$ estádio sucessional III $\left(1,50 \mathrm{Mg} \mathrm{ha}^{-1}\right)>$ estádio sucessional I $\left(1,47 \mathrm{Mg} \mathrm{ha}^{-1}\right)$.

Palavras-chave: Carbono orgânico, transferência de macronutrientes, serapilheira acumulada

\begin{abstract}
No matter what kind of forest it is, the litter production represents the first stage of nutrients and energy transfer from the vegetation to the soil, because most of the nutrients absorbed by the plants comes back to the forest ground through the fall of the litter or leaves wash. The aim of this study was to quantify the production of accumulated litter and nutrient contents on three successional stages of Atlantic Rain Forest, Blumenau/SC - Brazil. For the collections of the accumulated litter five rectangular samples units (SU) of $10 \mathrm{~m} \times 20 \mathrm{~m}$ were used in each successional stage, in a total of 15 SUs. In each SU the collections of material in an aleatory way was made with the aid of a metal frame of $0.25 \mathrm{mx} 0.25 \mathrm{~m}$, with five replications per SU every 30 days ( 75 samples/month, that is to say, 25 samples/successional
\end{abstract}

1 Prof $f^{\mathrm{D}}$ Dr. Departamento de Engenharia Florestal/Setor de Ciências Agrárias e Ambientais. Universidade Estadual do CentroOeste (UNICENTRO), Campus Universitário de Irati/PR. E-mail: caldeiramv@yahoo.com.br

2 Dr. Prof ${ }^{\circ}$ Departamento de Engenharia Florestal/CCT/FURB - Rua São Paulo, 3250 - Itoupava Seca - CEP: 89030-000, Blumenau/SC.

3 Acadêmicos do curso de Engenharia Florestal/CCT/FURB - Rua São Paulo, 3250 - Itoupava Seca - CEP: 89030-000, Blumenau/SC.

4 Prof $^{\circ}$ M.Sc. Departamento de Engenharia Ambiental/Setor de Ciências Agrárias e Ambientais. Universidade Estadual do CentroOeste (UNICENTRO), Campus Universitário de Irati. PR.

* Autor para correspondência 
stage). The average production of accumulated litter in twenty two months in the collected data was, in a decreasing order, stage III $\left(5.28 \mathrm{Mg} \mathrm{ha}^{-1}\right)>$ stage II $\left(5.02 \mathrm{Mg} \mathrm{ha}^{-1}\right)>$ stage I $\left(4.47 \mathrm{Mg} \mathrm{ha}^{-1}\right)$. The total macronutrient contents on accumulated litter of successional stages I and II, in decreasing order were: $\mathrm{N}>\mathrm{Ca}>\mathrm{Mg}>\mathrm{K}>\mathrm{S}>\mathrm{P}$, and on stage III: $\mathrm{N}>\mathrm{Ca}>\mathrm{Mg}>\mathrm{S}>\mathrm{K}>\mathrm{P}$. The forest presented total content of micronutrients on accumulated litter of three successional stages in the following decreasing order: $\mathrm{Fe}>\mathrm{Mn}>\mathrm{Zn}>\mathrm{B}>\mathrm{Cu}$. For the total organic carbon content on accumulated litter, the sequence was: stage II $\left(1.65 \mathrm{Mg} \mathrm{ha}^{-1}\right)>$ stage III $\left(1.50 \mathrm{Mg} \mathrm{ha}^{-1}\right)>$ stage I $\left(1.47 \mathrm{Mg} \mathrm{ha}^{-1}\right)$.

Key words: Organic carbon, macronutrients transfer, accumulated litter

\section{Introdução}

As florestas tropicais e subtropicais têm sido assunto de reconhecida importância, abrangendo vários aspectos como os relacionados ao clima, ao ciclo hidrológico, ao ciclo do carbono, à produção primária, à biodiversidade e, de forma crescente, aos aspectos culturais e sócio-econômicos e políticos. Mas mesmo assim, principalmente nos países em desenvolvimento, onde o crescimento populacional está em ascensão, tem-se verificado nos últimos anos uma ação antrópica sobre florestas nativas, através de queimadas e corte raso, com o objetivo de implantar lavouras agrícolas ou promover a exploração irracional dos produtos florestais. Um outro aspecto negativo do desmatamento é a erosão genética que está se processando rapidamente e isto tem que ser considerado em caráter de urgência (CALDEIRA, 2003).

O manejo sustentado é a administração da floresta visando à obtenção de benefícios econômicos e sociais, respeitando-se os mecanismos de sustentação do ecossistema. Diante desta definição, percebe-se o quanto é importante conhecer profundamente um ecossistema e seus componentes, pois para bem administrar um recurso, é preciso, antes de tudo, conhecê-lo completamente.

O princípio de manejo sustentado exige que as explorações nas florestas sejam feitas de maneira que o conteúdo remanescente possua condições de fornecer uma produção contínua e periódica e também que garanta a conservação da biodiversidade da floresta. Muitas vezes, uma das causas do manejo inadequado das florestas é o desconhecimento dos fatores que sustentam a alta produção de biomassa e, ainda, concomitantemente, que conservam a fertilidade do solo.

Trabalhos relacionados com a quantificação de serapilheira acumulada fornecem subsídios para um melhor entendimento da dinâmica dos nutrientes, pois esse tipo de pesquisa deverá ser em um período mínimo de dois anos. Além disso, permitirá à geração de informações que ajudem na escolha de espécies florestais para a formação de maciços, através da sazonalidade, da quantidade e da qualidade da serapilheira produzida, quando suas características químicas e físicas forem relevantes para a melhoria do solo e da cadeia alimentar resultante dos detritos por elas gerados.

O objetivo desse estudo foi quantificar a produção de serapilheira acumulada e o conteúdo de nutrientes em três estádios sucessionais da Floresta Ombrófila Densa em Blumenau/SC.

\section{Material e métodos}

A floresta em estudo, faz parte do Parque Natural Municipal Nascentes do Garcia (Parque das Nascentes) localizado no município de Blumenau/SC, pertencente a Universidade Regional de Blumenau e a Fundação Municipal do Meio Ambiente.

O Parque das Nascentes possui uma área de 5.300 ha, com $98 \%$ de coberturas arbóreas, caracterizadas por diferentes estádios de sucessão da Floresta Ombrófila Densa. O Parque está a $20 \mathrm{~km}$ do centro de Blumenau e localizado entre as latitudes $27^{\circ} 01^{\prime}$ e $27^{\circ}$ $06^{\prime} \mathrm{S}$ e entre as longitudes $49^{\circ} 01^{\prime} \mathrm{e} 49^{\circ} 10^{\prime} \mathrm{W}$, em altitude de 350 a 650 m s.n.m., na região sul do município de Blumenau (Figura 1) (SCHORN, 2005). 
Segundo a classificação climática de Thomthwaite, o clima da região é do tipo Úmido Mesotérmico, sem deficiência de chuva em qualquer estação e regime de evapotranspiração com potencial megatérmico. A precipitação anual varia entre $1.400 \mathrm{~mm}$ a $1.800 \mathrm{~mm}$, distribuídos entre 120 a 140 dias de chuva durante o ano, com umidade relativa média entre $75 \%$ a $80 \%$. A insolação total anual gira em torno de 1.800 horas, com uma temperatura média anual variando entre $18^{\circ} \mathrm{C}$ a $22^{\circ} \mathrm{C}$ (SANTA CATARINA, 1986).

De acordo com Santos (1996), a área do Parque das Nascentes está inserida na Serra do Itajaí, que faz parte da unidade geomorfológica da Serra do Tabuleiro, sendo constituído principalmente por agrupamentos de gnaisses, granitos e migmatitos. Estas antigas e diversificadas formações rochosas datam de mais de 500 milhões de anos.
Segundo a Empresa Brasileira de Pesquisa Agropecuária - EMBRAPA (1999), o solo que predomina no Parque das Nascentes é uma associação de CAMBISSOLO Eutrófico (CE), argila de atividade alta, gleico, A moderado, textura média + ARGISSOLO VERMELHO-AMARELO (PVA), argila de atividade baixa, A moderado, textura média/ argilosa.

Conforme Santos (1996) o Parque das Nascentes é banhado pelos afluentes da microbacia do ribeirão Garcia, afluente do rio Itajaí-Açu que, juntamente com os ribeirões da Velha e Itoupava, constitui-se no eixo principal de uma das principais microbacias do município de Blumenau. A calha, orientada no sentido SW/NE, possui extensão total de $41.890 \mathrm{~m}$. A microbacia abrange uma área de $404.580 \mathrm{~m}^{2}$.

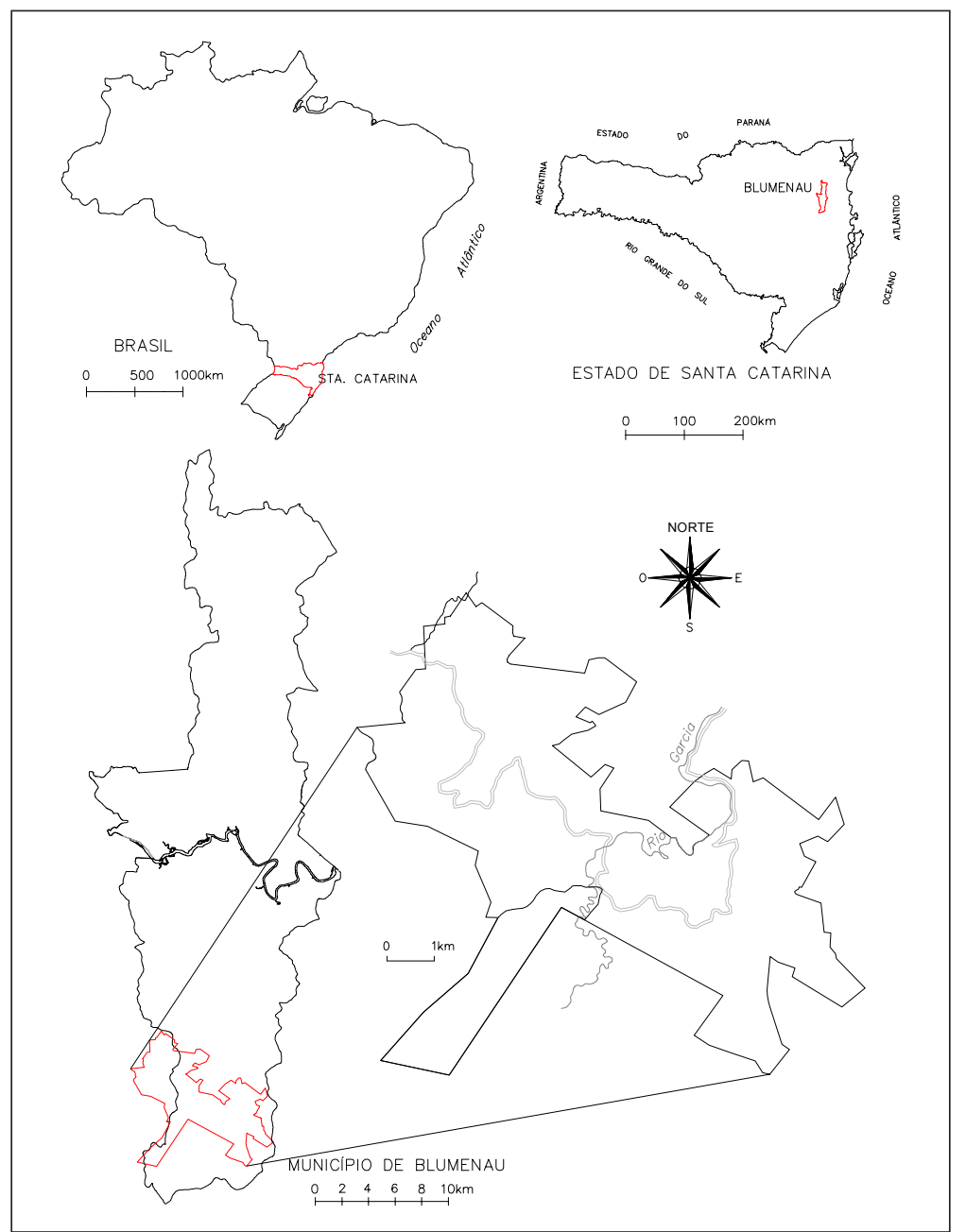

Figura 1. Parque Natural Municipal das Nascentes do Garcia localizado no município de Blumenau/SC. Fonte: Schorn (2005). 
A área onde foi efetuado o estudo enquadra-se como Floresta Ombrófila Densa Submontana, compreendendo três estádios: a) inicial; b) intermediário e c) avançado (SCHORN; GALVÃO, 2006).

De acordo com Schorn (2005), o estádio inicial é caracterizado por uma vegetação aberta, com poucos indivíduos arbóreos e predominância de espécies arbustivas e herbáceas e onde não houve ainda a formação de dossel e de estratos.

O estádio intermediário caracteriza-se por uma vegetação arbórea bastante densa, dominada ainda por espécies pioneiras e secundárias iniciais, em geral com baixa amplitude diamétrica. $O$ dossel é bastante fechado e já ocorrendo estratos verticais em formação (SCHORN, 2005). Como descrito por Roderjan e Kuniyoshi (1988) e Klein (1980), pode apresentar uma altura média entre 15 a 20 metros, ocorrendo seu desenvolvimento máximo entre $30 \mathrm{a}$ 40 anos; o estrato da regeneração é caracterizado principalmente por rubiáceas, piperáceas, amarantháceas e bromeliáceas, além de espécies arbóreas dominantes; no dossel, os principais representantes são: Miconia cinnamomifolia, Hieronyma alchorneoides, Miconia cabussu, Casearia sylvestris, Matayba guianensis, Cecropia sp., Alchornea triplinervia, entre outras.

O estádio avançado diferencia-se dos estádios anteriores pela composição florística e fitofisionomia, apresentando em geral, indivíduos de maior porte, tanto em altura, quanto em diâmetro. A cobertura é multiestratificada, cujo dossel pode atingir até 35 metros de altura. São típicos Ocotea Catharinensis, Sloanea guianensis, Virola bicuhyba, Alchornea triplinervia, Hyeronima alchorneoiddes, Cariniana estrellensis, Pseudopiptadenia warmingii, Cabralea canjerana, Cedrela fissilis. Ocorrem ainda, nos estratos inferiores, Garcinia gardneriana, Guapira opposita, Bathysa meridionalis, Psychotria nuda, Psychotria suterella, Euterpe edulis, Geonoma schottiana e Cyathea hirsuta (RODERJAN et al., 2002).

A amostragem da serapilheira acumulada foi realizada em três estádios sucessionais (inicial, intermediário e avançado) da Floresta Ombrófila Densa.

Para as coletas da serapilheira acumulada (outubro de 2004 a julho de 2005) foram utilizadas cinco unidades amostrais (UAs) retangulares de 10 m x 20 m em cada estádio sucessional, totalizando 15 UAs. Em cada UA com o auxílio de um gabarito de metal de $0,25 \mathrm{~m} \times 0,25 \mathrm{~m}$ foram realizados a coleta do material de estudo de forma aleatória com cinco repetições por UA a cada 30 dias (75 amostras/mês, ou seja, 25 amostras/estádio sucessional).

Para a determinação do peso seco das amostras de serapilheira acumulada as mesmas foram colocadas em sacos de papel, secas em estufa de circulação e renovação de ar a $65^{\circ} \mathrm{C}$ até alcançar massa seca constante, e que foi aferida em balança de precisão $(0,01 \mathrm{~g})$. A quantidade de serapilheira acumulada encontrada no gabarito de metal $\left(\mathrm{g} / 0,0625 \mathrm{~m}^{2}\right)$ foi estimada para $\mathrm{Mg} / \mathrm{ha} / \mathrm{mês}$. E em seguida triturada em moinho do tipo Wiley, passadas em peneiras de malha $1,0 \mathrm{~mm}$ (20 mesh) e armazenadas em frascos de vidros para subseqüente análise química (TEDESCO et al., 1995; MIYAZAWA et al., 1999).

No que se refere o tecido vegetal para a determinação dos macronutrientes, $\mathrm{o} N$ foi determinado no extrato de digestão sulfúrica pelo método Kjeldahl (destilação - titulação). Os outros elementos (P, K, Ca, Mg e S) foram determinados no extrato de digestão nítrico-perclórico, sendo $\mathrm{P}$ e $\mathrm{S}$ por espectrofotometria (UV-VIS), K por fotometria de chama e Ca e Mg por espectrofotometria de absorção atômica (MIYAZAWA et al., 1999). O carbono orgânico foi determinado segundo o método Walkley-Black (TEDESCO et al., 1995; MIYAZAWA et al., 1999).

Para cada estádio/mês foi calculada a Análise de Variância da quantidade de serapilheira acumulada. Com o objetivo de determinar diferença na serapilheira acumulada entre os estádios sucessionais de cada mês, cada estádio foi considerado como um tratamento. O delineamento utilizado foi inteiramente casualizado com vinte e cinco repetições em cada estádio. As médias de cada estádios/mês foram comparadas pelo teste de Tukey a 5\% de probabilidade. 


\section{Resultados e discussão}

\section{Produção de serapilheira acumulada}

A produção de serapilheira acumulada diferiu estatisticamente entre os estádios sucessionais (Tabela 1). Nos meses de dezembro/2004; janeiro, outubro, novembro e dezembro/2005; janeiro fevereiro, março e maio/2006, a produção de serapilheira acumulada não diferiu estatisticamente entre os estádios sucessionais I, II e III. No entanto, nos meses de outubro e novembro/2004 e junho/2005 não houve diferença estatística entre os estádios sucessionais I e II; e nos meses de maio, julho, agosto/ 2005 e julho/2006 não houve diferença estatística entre os estádios sucessionais II e III.

Analisando a produção de serapilheira acumulada em cada estádio/mês, a maior produção ocorreu no estádio sucessional III, exceto nos meses de abril, maio e setembro/2005 e fevereiro, março e junho/2006, em que a maior a produção ocorreu no estádio sucessional II e nos meses de outubro e novembro/2005 em que a maior produção foi no estádio I (Tabela 1).

Tabela 1. Valores médios de produção de serapilheira acumulada nos três estádios sucessionais da Floresta Ombrófila Densa, Blumenau/SC.

\begin{tabular}{|c|c|c|c|}
\hline \multirow{3}{*}{ Mês } & \multicolumn{3}{|c|}{ Média da serapilheira acumulada $\left(\mathrm{Mg} \mathrm{ha}^{-1}\right)$ nos estádios sucessionais } \\
\hline & $\mathrm{I}$ & II & III \\
\hline & \multicolumn{3}{|c|}{ Ano 2004} \\
\hline Outubro & $5,87 \mathrm{~b}$ & $5,41 \mathrm{~b}$ & $7,18 \mathrm{a}$ \\
\hline Novembro & $5,77 \mathrm{~b}$ & $6,91 \mathrm{~b}$ & 8,44 a \\
\hline Dezembro & $6,33 \mathrm{a}$ & $6,54 \mathrm{a}$ & $6,89 \mathrm{a}$ \\
\hline \multicolumn{4}{|c|}{ Ano 2005} \\
\hline Janeiro & $5,63 \mathrm{a}$ & $5,80 \mathrm{a}$ & $6,59 \mathrm{a}$ \\
\hline Fevereiro & $4,98 \mathrm{~b}$ & $5,91 \mathrm{ab}$ & 7,19 a \\
\hline Março & $4,92 \mathrm{~b}$ & $5,84 \mathrm{ab}$ & $6,39 \mathrm{a}$ \\
\hline Abril & $4,79 \mathrm{~b}$ & $6,10 \mathrm{a}$ & $5,40 \mathrm{ab}$ \\
\hline Maio & $4,54 \mathrm{~b}$ & $5,90 \mathrm{a}$ & $5,74 \mathrm{a}$ \\
\hline Junho & $5,10 \mathrm{~b}$ & $5,42 \mathrm{~b}$ & $6,34 \mathrm{a}$ \\
\hline Julho & $4,58 \mathrm{~b}$ & $6,12 \mathrm{a}$ & $6,61 \mathrm{a}$ \\
\hline Agosto & $4,58 \mathrm{~b}$ & $6,12 \mathrm{a}$ & $6,61 \mathrm{a}$ \\
\hline Setembro & $5,06 \mathrm{ab}$ & $5,32 \mathrm{a}$ & $3,81 \mathrm{~b}$ \\
\hline Outubro & $4,87 \mathrm{a}$ & $4,66 \mathrm{a}$ & $4,35 \mathrm{a}$ \\
\hline Novembro & $4,87 \mathrm{a}$ & $4,66 \mathrm{a}$ & $4,35 \mathrm{a}$ \\
\hline Dezembro & $4,81 \mathrm{a}$ & $4,60 \mathrm{a}$ & $4,83 \mathrm{a}$ \\
\hline \multicolumn{4}{|c|}{ Ano 2006} \\
\hline Janeiro & $3,78 \mathrm{a}$ & $3,59 \mathrm{a}$ & $4,04 \mathrm{a}$ \\
\hline Fevereiro & $3,33 \mathrm{a}$ & $3,77 \mathrm{a}$ & $3,74 \mathrm{a}$ \\
\hline Março & $2,96 \mathrm{a}$ & $3,54 \mathrm{a}$ & $3,26 \mathrm{a}$ \\
\hline Abril & $2,89 \mathrm{~b}$ & $3,58 \mathrm{ab}$ & $3,84 \mathrm{a}$ \\
\hline Maio & $3,24 \mathrm{a}$ & $3,47 \mathrm{a}$ & $3,64 \mathrm{a}$ \\
\hline Junho & $2,74 \mathrm{~b}$ & $3,55 \mathrm{a}$ & $2,91 \mathrm{ab}$ \\
\hline Julho & $2,61 \mathrm{~b}$ & $3,64 \mathrm{a}$ & $3,93 \mathrm{a}$ \\
\hline Média Geral $^{1}$ & 4,47 & 5,02 & 5,28 \\
\hline
\end{tabular}

${ }^{1}$ Valores médio referente aos vinte e dois meses de coleta; ${ }^{2}$ Médias na vertical não ligada por mesma letra diferem pelo teste de Tukey a 5\% de probabilidade. 
Vários fatores podem influenciar nas diferenças entre a serapilheira acumulada na floresta nos diferentes estádios do presente estudo, bem como com os outros tipos de floresta. Toda a dinâmica do material acumulado na superfície do solo é influenciada por fatores do ambiente, temperatura e umidade; pela qualidade inicial do material formador como, por exemplo, pelos componentes orgânicos; pelos macro e micronutrientes; pelos organismos do solo, como fauna, actomicetos e bactérias entre outros (O'CONNELL; SANKARAN, 1997; WEDDERBURN; CARTER, 1999).

Conforme O'Connell e Sankaran (1997) em determinados locais da América do Sul a produção de serapilheira acumulada de florestas tropicais naturais varia entre 3,1 e 16,5 Mg/ha. Nesse sentido, o valor máximo $(16,5 \mathrm{Mg} / \mathrm{ha})$ é observado nas florestas submontanas, na Colômbia. Florestas montanas, geralmente acumulam mais serapilheira do que outras florestas tropicais naturais (TANNER, 1980), provavelmente por causa do baixo teor de nutrientes nas folhas e principalmente devido aos fatores climáticos, os quais resultam numa deposição lenta.

O estoque médio de serapilheira acumulada da Floresta Ombrófila Densa variou de 4,47 Mg/ha a $5,28 \mathrm{Mg} /$ ha (Tabela 1), valor este inferior aos observados em cinco florestas semidecíduas no sudeste do Brasil, com valores que variaram de 5,5 $\mathrm{Mg} / \mathrm{ha}$ a $8,6 \mathrm{Mg} / \mathrm{ha}$ (MORELLATO, 1992). No entanto, Cunha (1997) realizou estudo de biomassa na serapilheira acumulada em Floresta Estacional no Rio Grande do Sul, em diferentes estágios de sucessão: capoeira com 13 anos, capoeirão com 19 anos e floresta secundária com mais de 30 anos, nas quais foram encontrados os seguintes valores: 4,2 $\mathrm{Mg} \mathrm{ha}^{-1}, 5,6 \mathrm{Mg} \mathrm{ha}^{-1}$ e 6,0 $\mathrm{Mg} \mathrm{ha}^{-1}$, respectivamente. Brun et al. (2001) na Floresta Estacional Decidual no Rio Grande do Sul, também realizaram a quantificação de biomassa da serapilheira acumulada em diferentes estágios sucessionais. Foram considerados os seguintes estágios de sucessão e a quantidade de serapilheira acumulada: capoeirão $(5,1$ $\left.\mathrm{Mg} \mathrm{ha}^{-1}\right)$, floresta secundária $\left(5,7 \mathrm{Mg} \mathrm{ha}^{-1}\right)$ e floresta madura $\left(7,1 \mathrm{Mg} \mathrm{ha}^{-1}\right)$.

$\mathrm{O}$ acúmulo de serapilheira varia em função da procedência, da espécie, da cobertura florestal, do estágio sucessional, da idade, da época da coleta, do tipo de floresta e do local. Além desses fatores, outros como: condições edafoclimáticas e regime hídrico, condições climáticas, sítio, sub-bosque, manejo silvicultural, proporção de copa, bem como taxa de decomposição e distúrbios naturais como fogo e ataque de insetos ou artificiais como remoção da serapilheira e cultivos, ocorridos na floresta ou no povoamento, também influenciam no acúmulo de serapilheira.

O acúmulo de serapilheira encontrado na floresta do presente estudo apresenta alguns resultados não similares a outros tipos de floresta, conforme mostra a Tabela 2 .

\section{Macronutrientes na serapilheira acumulada}

O conteúdo total de macronutrientes na serapilheira acumulada em ordem decrescente no estádio sucessional I e II foram: $\mathrm{N}>\mathrm{Ca}>\mathrm{Mg}>\mathrm{K}>$ $\mathrm{S}>\mathrm{P}$, no estádio sucessional III: $\mathrm{N}>\mathrm{Ca}>\mathrm{Mg}>\mathrm{S}>$ $\mathrm{K}>\mathrm{P}$ (Tabelas 3, 4 e 5).

Independente do estádio sucessional, a serapilheira acumulada na Floresta Ombrófila Densa foi a principal via de transferência de $\mathrm{N}>\mathrm{Ca}>\mathrm{Mg}$ para o solo. Delitti (1984) observou que ocorre uma variação nos teores de macro e micronutrientes na serapilheira acumulada da mata ciliar e do campo cerrado, na região de Mogi-Guaçu, SP. Essa variação também ocorre em função da época de coleta da serapilheira acumulada nestes ecossistemas. A serapilheira acumulada foi a principal via de transferência de $\mathrm{N}>\mathrm{Ca}>\mathrm{Mg}>\mathrm{S}$ para o solo, independente da época de coleta na mata ciliar e do cerrado. 
Tabela 2. Serapilheira acumulada em algumas florestas do mundo.

\begin{tabular}{|c|c|c|}
\hline Tipo de floresta & Local & Serapilheira $\left(\mathrm{Mg} \mathrm{ha}^{-1}\right)$ \\
\hline \multirow[b]{2}{*}{${ }^{1}$ Floresta Tropical (área montanhosa) } & Porto Rico & 8,1 \\
\hline & Nova Guiné & 7,7 \\
\hline \multirow{3}{*}{${ }^{1}$ Floresta Decídua (clima temperado) } & Missouri, U.S.A & 8,2 \\
\hline & Tenessee, U.S.A & 7,6 \\
\hline & Minesota, U.S.A & 8,4 \\
\hline${ }^{1}$ Floresta Tropical (terras baixas) & Nova Guiné & 8,2 \\
\hline${ }^{2}$ Floresta Tropical (clímax) & Araras, SP & 8,2 \\
\hline${ }^{3}$ Floresta Tropical Úmida & Borneo, Malásia & 8,5 \\
\hline \multirow{2}{*}{$\begin{array}{l}{ }^{4} \text { Floresta Ombrófila Mista (tipo floresta I) }{ }^{(1)} \\
{ }^{4} \text { Floresta Ombrófila Mista (tipo floresta II) }{ }^{(2)}\end{array}$} & Caçador, SC & 9,7 \\
\hline & & 7,5 \\
\hline $\begin{array}{l}{ }^{5} \text { Floresta Ombrófila Mista Montana (estádio I) }{ }^{(3)} \\
{ }^{5} \text { Floresta Ombrófila Mista Montana (estádio II) }{ }^{(4)} \\
{ }^{5} \text { Floresta Ombrófila Mista Montana (estádio III) }{ }^{(5)}\end{array}$ & General Carneiro, PR & $\begin{array}{l}7,9 \\
8,6 \\
7,6 \\
\end{array}$ \\
\hline
\end{tabular}

Nota: ${ }^{(1)}$ Predominância de Araucaria angustifolia no estrato superior; ${ }^{(2)}$ Local onde a diversidade de espécies é maior, com predominância de outras espécies no estrato superior; ${ }^{(3)}$ Estádio inicial; ${ }^{(4)}$ Estádio intermediário; ${ }^{(5)}$ Estádio avançado.

Tabela 3. Valores médios do conteúdo de macronutrientes da serapilheira acumulada no estádio sucessional I da Floresta Ombrófila Densa, Blumenau/SC.

\begin{tabular}{|c|c|c|c|c|c|c|}
\hline \multirow{2}{*}{ Mês } & \multicolumn{6}{|c|}{ Macronutrientes $\left(\mathrm{kg} \mathrm{ha}^{-1}\right)$} \\
\hline & $\mathrm{N}$ & $\mathrm{P}$ & $\mathrm{K}$ & $\mathrm{Ca}$ & $\mathrm{Mg}$ & $\mathrm{S}$ \\
\hline \multicolumn{7}{|c|}{ Ano 2004} \\
\hline Outubro & 81,43 & 3,46 & 12,85 & 63,53 & 18,23 & 10,94 \\
\hline Novembro & 83,72 & 3,63 & 15,00 & 70,10 & 20,02 & 6,92 \\
\hline Dezembro & 99,33 & 4,12 & 14,31 & 75,97 & 25,70 & 11,27 \\
\hline \multicolumn{7}{|c|}{ Ano $2005^{1}$} \\
\hline Janeiro & 83,54 & 3,60 & 11,21 & 68,44 & 20,20 & 10,67 \\
\hline Abril & 63,88 & 2,67 & 13,23 & 33,38 & 15,36 & 13,31 \\
\hline Maio & 73,83 & 3,19 & 13,18 & 30,40 & 11,24 & 4,61 \\
\hline Junho & 77,69 & 2,97 & 14,02 & 35,26 & 17,13 & 10,21 \\
\hline Julho & 70,08 & 2,58 & 16,57 & 32,34 & 11,97 & 10,68 \\
\hline Agosto & 64,04 & 2,56 & 15,01 & 26,08 & 9,05 & 8,12 \\
\hline Setembro & 77,01 & 3,54 & 10,35 & 51,77 & 14,83 & 9,46 \\
\hline Outubro & 88,78 & 3,11 & 8,64 & 61,46 & 13,37 & 9,61 \\
\hline Novembro & 81,56 & 2,92 & 9,97 & 51,54 & 11,81 & 9,22 \\
\hline Dezembro & 77,14 & 3,46 & 17,56 & 44,27 & 14,48 & 5,82 \\
\hline \multicolumn{7}{|c|}{ Ano 2006} \\
\hline Janeiro & 55,73 & 2,39 & 11,24 & 36,03 & 10,47 & 4,20 \\
\hline Fevereiro & 48,15 & 1,53 & 11,23 & 34,12 & 12,16 & 3,43 \\
\hline Março & 48,34 & 1,63 & 12,62 & 29,53 & 9,63 & 2,81 \\
\hline Abril & 47,11 & 0,90 & 4,27 & 14,76 & 4,77 & 3,32 \\
\hline Maio & 45,67 & 0,97 & 7,41 & 13,37 & 4,89 & 2,43 \\
\hline Junho & 42,25 & 0,98 & 4,15 & 10,49 & 3,82 & 2,45 \\
\hline Julho & 39,80 & 1,98 & 12,65 & 21,59 & 7,90 & 2,53 \\
\hline Média Geral $^{2}$ & 67,45 & 2,61 & 11,77 & 40,22 & 12,85 & 7,10 \\
\hline
\end{tabular}

${ }^{1}$ Não foi realizada a análise de tecido de macronutrientes na serapilheira acumulada nos meses fevereiro e março de 2005. ${ }^{2}$ Valor médio referente aos vinte meses de coleta. 
Caldeira (2003) em seu estudo na Floresta Ombrófila Mista Montana no PR evidencia claramente que a serapilheira acumulada é a principal via de transferência de N, K e Ca para o solo, demonstrando assim a importância do material formado da serapilheira no processo de ciclagem biogeoquímica de nutrientes em sítios florestais, principalmente para o N, o K e o Ca (GRUSAK; POMPER, 1999).

Tabela 4. Valores médios do conteúdo de macronutrientes da serapilheira acumulada no estádio sucessional II da Floresta Ombrófila Densa, Blumenau/SC.

\begin{tabular}{|c|c|c|c|c|c|c|}
\hline \multirow{2}{*}{ Mês } & \multicolumn{6}{|c|}{ Macronutrientes $\left(\mathrm{kg} \mathrm{ha}^{-1}\right)$} \\
\hline & $\mathrm{N}$ & $\bar{P}$ & $\mathrm{~K}$ & $\mathrm{Ca}$ & $\mathrm{Mg}$ & $\mathrm{S}$ \\
\hline \multicolumn{7}{|c|}{ Ano 2004} \\
\hline Outubro & 77,26 & 3,18 & 9,64 & 82,78 & 16,75 & 9,55 \\
\hline Novembro & 106,15 & 4,35 & 14,24 & 102,69 & 20,18 & 12,78 \\
\hline Dezembro & 100,98 & 4,13 & 15,33 & 100,68 & 19,33 & 8,72 \\
\hline \multicolumn{7}{|c|}{ Ano $2005^{1}$} \\
\hline Janeiro & 78,37 & 3,43 & 8,03 & 104,67 & 18,04 & 7,42 \\
\hline Abril & 89,95 & 3,45 & 12,66 & 68,41 & 16,52 & 6,29 \\
\hline Maio & 85,18 & 3,61 & 11,98 & 60,36 & 19,23 & 12,31 \\
\hline Junho & 82,08 & 2,82 & 9,64 & 92,14 & 14,21 & 10,72 \\
\hline Julho & 84,84 & 2,94 & 21,28 & 66,79 & 13,15 & 7,48 \\
\hline Agosto & 84,16 & 2,96 & 18,36 & 75,17 & 12,60 & 12,57 \\
\hline Setembro & 85,87 & 3,21 & 10,16 & 64,24 & 13,85 & 8,46 \\
\hline Outubro & 80,48 & 3,56 & 12,09 & 42,00 & 11,38 & 7,46 \\
\hline Novembro & 78,21 & 3,95 & 15,91 & 40,45 & 12,64 & 8,83 \\
\hline Dezembro & 69,95 & 2,76 & 19,71 & 53,69 & 11,79 & 3,36 \\
\hline \multicolumn{7}{|c|}{ Ano 2006} \\
\hline Janeiro & 56,26 & 1,98 & 8,20 & 47,09 & 10,43 & 4,31 \\
\hline Fevereiro & 51,64 & 1,81 & 8,94 & 66,28 & 13,58 & 5,28 \\
\hline Março & 50,81 & 2,12 & 11,21 & 64,67 & 11,42 & 4,03 \\
\hline Abril & 51,77 & 0,90 & 4,16 & 2,01 & 5,84 & 3,87 \\
\hline Maio & 48,91 & 0,87 & 5,63 & 19,21 & 5,63 & 2,29 \\
\hline Junho & 46,00 & 1,14 & 6,20 & 18,40 & 5,34 & 6,09 \\
\hline Julho & 52,72 & 2,29 & 10,59 & 46,68 & 10,73 & 3,78 \\
\hline Média Geral $^{2}$ & 73,08 & 2,77 & 11,70 & 60,92 & 13,13 & 7,28 \\
\hline
\end{tabular}

${ }^{1}$ Não foi realizada a análise de tecido de macronutrientes na serapilheira acumulada nos meses fevereiro e março de 2005. ${ }^{2}$ Valor médio referente aos vinte meses de coleta.

Estudo realizado por Brun, Schumacher e Vaccaro (1999) observaram que em 3 fases sucessionais, em uma Floresta Estacional Decidual no Rio Grande do Sul, que o retorno de nutrientes através da serapilheira possui maior razão de proporcionalidade com a quantidade de serapilheira devolvida do que com os teores dos nutrientes na mesma.

De acordo com Caldeira (2003) diferentes teores, bem como conteúdos, de macronutrientes na serapilheira acumulada podem estar relacionados com a mobilidade dos bioelementos dentro da planta, por exemplo, o K, tornando-o sujeito à lixiviação. A alta variabilidade dos teores de K na serapilheira, segundo Neves (2000) e Pagano e Durigan (2000), entre as épocas de avaliação, guarda relação com a variação da precipitação pluviométrica, o que se explica pela sua alta suscetibilidade à lixiviação via lavagem de folhas e de serapilheira, que decorrem do fato de o K não participar de compostos orgânicos, ocorrendo na forma solúvel ou adsorvido no suco celular (MARSCHNER, 1997). A ciclagem do K na relação solo-planta, é mais rápida do que a de outros nutrientes, por se tratar de um cátion monovalente (JORDAN, 1985). No entanto, macronutrientes como 
$\mathrm{Ca}, \mathrm{Mg}$ e $\mathrm{S}$, embora considerados como moderadamente laváveis, pois segundo Tukey Júnior e Tukey (1962 apud PAGANO; DURIGAN, 2000), mostram variações menores nos teores.

Considerando somente os macronutrientes, $\mathrm{o} \mathrm{Ca}$ apresentou o segundo maior teor e conteúdo na serapilheira acumulada (Tabelas 3, 4 e 5), fato este que pode estar relacionado com a sua pouca mobilidade nos tecidos vegetais e com a longevidade das folhas. A baixa mobilidade deste macronutriente dentro dos tecidos vegetais é citada por Nilsson et al. (1995) como um fator que determina que a maior quantidade de ciclagem deste nutriente na natureza seja feita pela queda e decomposição dos tecidos vegetais senescentes.
Os baixos teores de $\mathrm{K}$ na serapilheira acumulada estão relacionados com pequenas taxas desse nutriente na ciclagem biogeoquímica, contrariamente às de $\mathrm{Ca}$, nutriente cujos teores na serapilheira acumulada são muitas vezes superiores aos existentes nos componentes da biomassa acima do solo. A ciclagem biogeoquímica, de modo geral, é a via pela qual os nutrientes de baixa mobilidade na planta são ciclados, uma vez que para esses nutrientes a ciclagem bioquímica torna-se pouca expressiva, contrariamente ao que ocorre para nutrientes de alta mobilidade na planta (CALDEIRA, 2003).

Tabela 5. Valores médios do conteúdo de macronutrientes da serapilheira acumulada no estádio sucessional III da Floresta Ombrófila Densa, Blumenau/SC.

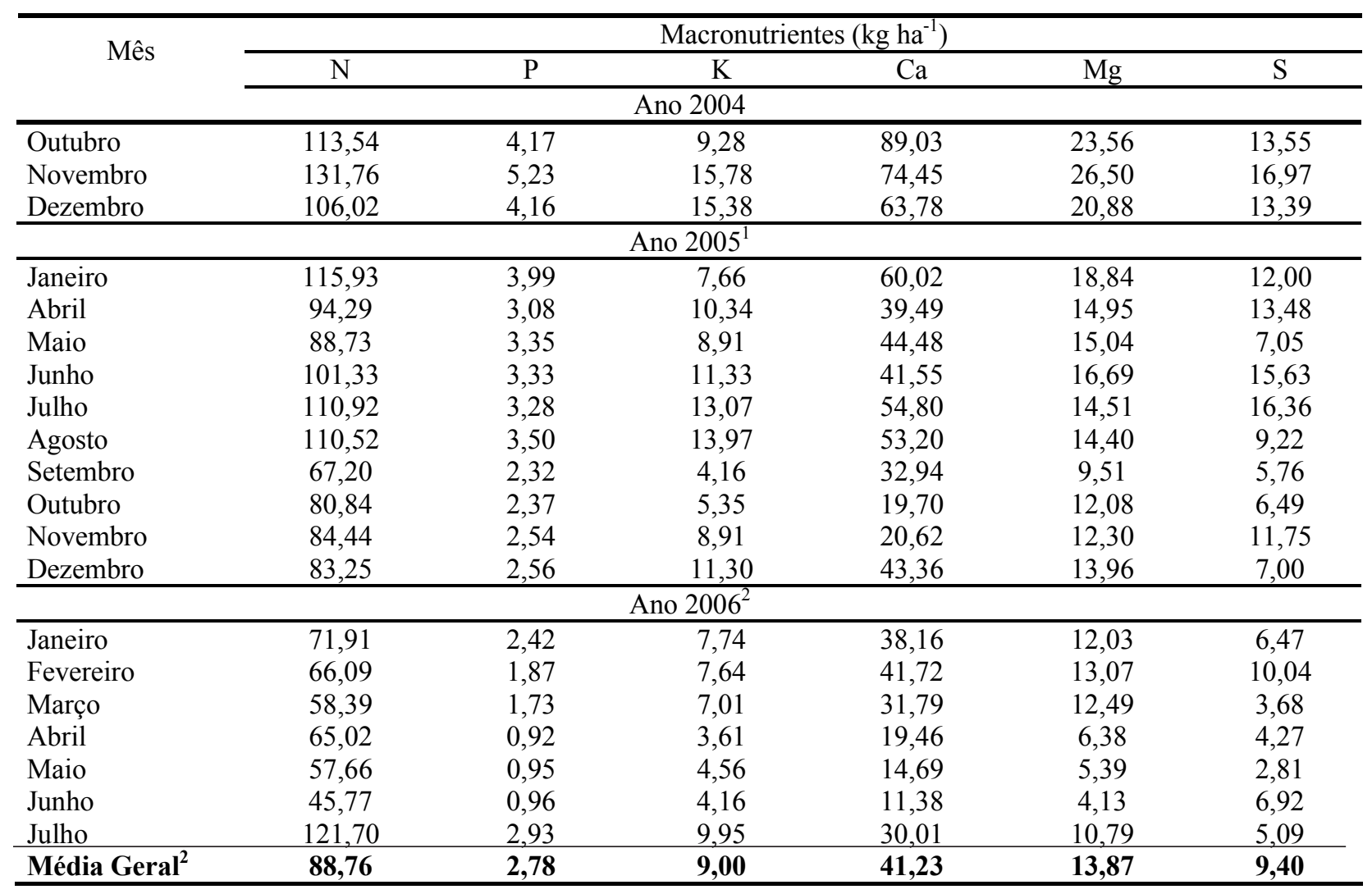

${ }^{1}$ Não foi realizada a análise de tecido de macronutrientes na serapilheira acumulada nos meses fevereiro e março de 2005. ${ }^{2}$ Valor médio referente aos vinte meses de coleta. 


\section{Micronutrientes na serapilheira acumulada}

Pode-se observar nas Tabelas 6, 7 e 8 que independente do estádio sucessional a serapilheira acumulada foi a principal via de transferência de Fe, Mn e Zn para o solo.

A floresta em estudo apresentou para o conteúdo total de micronutrientes na serapilheira acumulada nos três estádios sucessionais, a seguinte ordem decrescente: $\mathrm{Fe}>\mathrm{Mn}>\mathrm{Zn}>\mathrm{B}>\mathrm{Cu}$. Essa seqüência também é observada em uma Floresta Ombrófila Mista Montana, PR (CALDEIRA, 2003).

Os maiores teores e conteúdos, principalmente de Fe na serapilheira acumulada podem ser justificados pela sua mobilidade. Pois, segundo Dechen e Nachtigall (2006) e Malavolta (2006), em relação ao metabolismo do Fe na planta, deve-se levar em conta que este apresenta baixa mobilidade nos tecidos vegetais. Essa mobilidade é afetada, negativamente, por vários fatores, como elevado conteúdo de $\mathrm{P}$, deficiência de $\mathrm{K}$, quantidade elevada de $\mathrm{Mn}$ e baixa intensidade luminosa (DECHEN; NACHTIGALL, 2006). A outra justificativa pode ser em função dos maiores teores nas folhas velhas de algumas espécies, bem como teores médios maiores nas folhas da floresta em relação à madeira, casca $\mathrm{e}$ galhos (CALDEIRA, 2003).

A contaminação com o solo, ou seja, amostra de serapilheira com solo pode ser considerada como uma outra justificativa. Os conteúdos de argila e matéria orgânica no solo (MOS) influencia também na disponibilidade do Fe, já que solos argilosos existem tendência de reter o $\mathrm{Fe}$, ao passo que os teores adequados de MOS proporcionam melhor

Tabela 6. Valores médios do conteúdo de micronutrientes da serapilheira acumulada no estádio sucessional I da Floresta Ombrófila Densa, Blumenau/SC.

\begin{tabular}{|c|c|c|c|c|c|}
\hline \multirow{2}{*}{ Mês } & \multicolumn{5}{|c|}{ Micronutrientes $\left(\mathrm{kg} \mathrm{ha}^{-1}\right)$} \\
\hline & $\mathrm{B}$ & $\mathrm{Cu}$ & $\mathrm{Fe}$ & $\mathrm{Mn}$ & $\mathrm{Zn}$ \\
\hline \multicolumn{6}{|c|}{ Ano 2004} \\
\hline Outubro & 0,09 & 0,08 & 18,34 & 5,46 & 0,21 \\
\hline Novembro & 0,10 & 0,08 & 7,45 & 5,69 & 0,22 \\
\hline Dezembro & 0,12 & 0,09 & 11,67 & 8,27 & 0,29 \\
\hline \multicolumn{6}{|c|}{ Ano $2005^{1}$} \\
\hline Janeiro & 0,10 & 0,08 & 11,66 & 7,62 & 0,23 \\
\hline Abril & 0,08 & 0,06 & 4,51 & 6,79 & 0,17 \\
\hline Maio & 0,07 & 0,06 & 5,48 & 5,75 & 0,47 \\
\hline Junho & 0,09 & 0,07 & 5,97 & 9,18 & 0,23 \\
\hline Julho & 0,08 & 0,06 & 11,43 & 5,53 & 0,19 \\
\hline Agosto & 0,08 & 0,05 & 15,18 & 6,08 & 0,18 \\
\hline Setembro & 0,14 & 0,07 & 11,55 & 5,05 & 0,18 \\
\hline Outubro & 0,13 & 0,07 & 10,66 & 12,55 & 0,20 \\
\hline Novembro & 0,14 & 0,08 & 22,67 & 10,65 & 0,20 \\
\hline Dezembro & 0,14 & 0,07 & 13,96 & 6,29 & 0,22 \\
\hline \multicolumn{6}{|c|}{ Ano 2006} \\
\hline Janeiro & 0,10 & 0,05 & 12,86 & 4,82 & 0,18 \\
\hline Fevereiro & 0,09 & 0,05 & 7,56 & 5,33 & 0,13 \\
\hline Março & 0,07 & 0,04 & 7,91 & 4,81 & 0,12 \\
\hline Abril & 0,09 & 0,02 & 1,66 & 2,01 & 0,12 \\
\hline Maio & 0,09 & 0,02 & 6,30 & 1,47 & 0,04 \\
\hline Junho & 0,07 & 0,02 & 1,48 & 1,59 & 0,05 \\
\hline Julho & 0,09 & 0,04 & 2,26 & 3,33 & 0,09 \\
\hline Média Geral $^{2}$ & 0,10 & 0,06 & $\mathbf{9 , 5 3}$ & 5,91 & 0,19 \\
\hline
\end{tabular}

${ }^{1}$ Não foi realizada a análise de tecido de micronutrientes na serapilheira acumulada nos meses fevereiro e março de 2005. ${ }^{2}$ Valore médio referente aos vinte meses de coleta. 
aproveitamento do Fe plantas, devido às suas características acidificantes e redutoras, bem como com à capacidade de determinadas substâncias húmicas para formar quelatos em condições adversas de pH (DECHEN; NACHTIGALL, 2006). O conteúdo de Fe no solo é influenciado pelo $\mathrm{pH}$, pois o Fe férrico aumenta com o aumento da acidez, atingindo grandes teores em solos muito ácidos, com $\mathrm{pH}$ menores que 3, e em solos ricos em ácidos húmicos e colóides capazes de formar complexos solúveis com Fe (DECHEN; NACHTIGALL, 2006; MALAVOLTA, 2006). Segundo Malavolta (2006), o teor de Fe no solo é conseqüência do conteúdo no material de origem.

Segundo Caldeira (2003) da quantidade total de todos os micronutrientes analisados na biomassa radicial em uma Floresta Ombrófila Mista Montana, a contribuição do $\mathrm{Fe}$ foi de aproximadamente de $76,1 \%$ em relação à quantidade total de todos os micronutrientes. Isso pode devido de a contaminação com o solo, pois trabalhos com biomassa radicial, as raízes devem ser bem lavadas.

O segundo micronutriente com maior conteúdo na serapilheira acumulada é o Mn. Esse fato pode ser também em função da contaminação com o solo, ou seja, amostra de serapilheira com solo, pois o Mn $\mathrm{n}$ solo é proveniente de óxidos, carbonatos, silicatos e sulfetos. Os óxidos e sulfetos de Mn são as formas encontradas $\mathrm{cm}$ mais freqüência nos solos, sendo comum a sua ocorrência em associação com Fe (DECHEN; NACHTIGALL, 2006).

Cabe ressaltar também que s maiores teores e conteúdos de Mn na serapilheira acumulada podem ser justificados pelos seus maiores teores nas folhas de algumas espécies. Conforme Heenan e Campbell (1980), na condição de bom suprimento de Mn, as folhas acumulam altas concentrações conforme avança a idade da planta, sendo uma pequena parcela do elemento translocada das folhas velhas para as novas em crescimento, onde o elemento se encontra em menor concentração. Contudo, deve-se considerar que a concentração de Mn na planta varia grandemente entre partes da planta e da espécie (CALDEIRA, 2003; DECHEN; NACHTIGALL, 2006), bem como durante o período vegetativo (DECHEN; NACHTIGALL, 2006).

Rodríguez Jiménez (1988) em um Bosque Pluvial de Terras Baixas na Colômbia e Schumacher et al. (2002) em plantios de Araucaria angustifolia com 14 anos de idade também constataram que a serapilheira acumulada foi a principal via de transferência de Fe, Mn e Zn para o solo.

$\mathrm{O}$ B é o quarto micronutriente em teor e, conseqüentemente, em conteúdo na serapilheira acumulada, sendo que esse fato pode estar relacionado com a sua pouca mobilidade nos tecidos vegetais. Deste modo, quanto mais velha a folha maior o teor de B (JONES JÚNIOR, 1970). A mobilidade intermediária do B dentro dos tecidos vegetais (mobilidade intermediária no floema) (MARSCHNER, 1997) pode ser um dos fatores que determinam que a maior intensidade de ciclagem deste nutriente na natureza seja produzida pela queda e decomposição dos tecidos senescentes.

A literatura mostra que como regra geral o boro é imóvel na planta, isto é, não se move das folhas ou de outros órgãos para atender a necessidade do crescimento (BROWN; HU, 1998). No entanto, atualmente o boro é móvel no floema de todas das espécies (ex: amendoeiras, macieras e nectarinas) que utilizam polióis, ou seja, complexos de açúcares simples com álcool (ex: sorbitol, manitol, dulcitol) como um metabólito fotossintético primário. Nestas espécies, um complexo poliol-B-poliol é formado nos tecidos fotossintéticos e é transportado para no floema para drenos ativos, como por exemplo meristemas vegetivos ou reprodutivos. Contudo, em espécies que não produzem quantidades significativas de polióis, o boro, uma vez transportado até a folha através do fluxo respiratório (xilema), não pode entra no floema, resultando assim na sua complexa imobilidade (BROWN; HU, 1998; YAMADA, 2000). 
Tabela 7. Valores médios do conteúdo de micronutrientes da serapilheira acumulada no estádio sucessional II da Floresta Ombrófila Densa, Blumenau/SC.

\begin{tabular}{|c|c|c|c|c|c|}
\hline \multirow{2}{*}{ Mês } & \multicolumn{5}{|c|}{ Micronutrientes $\left(\mathrm{kg} \mathrm{ha}^{-1}\right)$} \\
\hline & B & $\mathrm{Cu}$ & $\mathrm{Fe}$ & $\mathrm{Mn}$ & $\mathrm{Zn}$ \\
\hline \multicolumn{6}{|c|}{ Ano 2004} \\
\hline Outubro & 0,07 & 0,10 & 8,88 & 12,11 & 0,21 \\
\hline Novembro & 0,12 & 0,12 & 11,79 & 13,08 & 0,25 \\
\hline Dezembro & 0,12 & 0,10 & 13,47 & 9,47 & 0,22 \\
\hline \multicolumn{6}{|c|}{ Ano $2005^{1}$} \\
\hline Janeiro & 0,08 & 0,09 & 8,99 & 11,14 & 0,20 \\
\hline Abril & 0,12 & 0,10 & 9,26 & 14,57 & 0,20 \\
\hline Maio & 0,12 & 0,11 & 7,03 & 13,59 & 0,24 \\
\hline Junho & 0,11 & 0,16 & 3,73 & 12,18 & 0,18 \\
\hline Julho & 0,11 & 0,10 & 16,75 & 11,88 & 0,21 \\
\hline Agosto & 0,09 & 0,11 & 15,54 & 11,55 & 0,20 \\
\hline Setembro & 0,15 & 0,11 & 16,24 & 9,65 & 0,23 \\
\hline Outubro & 0,13 & 0,05 & 18,71 & 5,72 & 0,19 \\
\hline Novembro & 0,12 & 0,06 & 24,14 & 4,94 & 0,19 \\
\hline Dezembro & 0,13 & 0,08 & 21,54 & 6,80 & 0,20 \\
\hline \multicolumn{6}{|c|}{ Ano 2006} \\
\hline Janeiro & 0,11 & 0,06 & 3,93 & 7,83 & 0,13 \\
\hline Fevereiro & 0,09 & 0,06 & 2,03 & 12,31 & 0,12 \\
\hline Março & 0,11 & 0,05 & 3,07 & 10,28 & 0,12 \\
\hline Abril & 0,11 & 0,03 & 1,33 & 5,26 & 0,14 \\
\hline Maio & 0,10 & 0,02 & 3,54 & 4,54 & 0,04 \\
\hline Junho & 0,10 & 0,03 & 7,29 & 4,61 & 0,08 \\
\hline Julho & 0,14 & 0,06 & 2,69 & 9,97 & 0,04 \\
\hline Média Geral $^{2}$ & 0,11 & 0,08 & 10,00 & 9,57 & 0,17 \\
\hline
\end{tabular}

${ }^{1}$ Não foi realizada a análise de tecido de micronutrientes na serapilheira acumulada nos meses fevereiro e março de 2005. ${ }^{2}$ Valore médios referente aos dezenove meses de coleta.

Sem dúvida alguma, a evidência da mobilidade de um nutriente no floema também pode ser verificada através da sua distribuição dentro dos diferentes órgãos de uma mesma planta. Nesse sentido, além do teor do nutriente nos diferentes órgãos, o teor de um determinado nutriente nas folhas com diferentes idades de uma mesma espécie também pode fornecer evidências no que se refere a mobilidade dos nutrientes. A ocorrência e dos maiores teores de boro em folhas velhas ou maduras comparadas com as folhas mais jovens são uma indicação da mobilidade do boro, pois estas folhas mais jovens transpiram menos água do que as folhas mais velhas. A diferença no local de acumulação de boro no tecidos de uma mesma planta, irão determinar onde, ocorrerão os sintomas de toxicidade de boro (BROWN; HU, 1998). 
Tabela 8. Valores médios do conteúdo de micronutrientes da serapilheira acumulada no estádio sucessional III da Floresta Ombrófila Densa, Blumenau/SC.

\begin{tabular}{|c|c|c|c|c|c|}
\hline \multirow{2}{*}{ Mês } & \multicolumn{5}{|c|}{ Micronutrientes $\left(\mathrm{kg} \mathrm{ha}^{-1}\right)$} \\
\hline & $\mathrm{B}$ & $\mathrm{Cu}$ & $\mathrm{Fe}$ & $\mathrm{Mn}$ & $\mathrm{Zn}$ \\
\hline \multicolumn{6}{|c|}{ Ano 2004} \\
\hline Outubro & 0,11 & 0,12 & 13,93 & 8,57 & 0,27 \\
\hline Novembro & 0,12 & 0,14 & 13,44 & 9,77 & 0,33 \\
\hline Dezembro & 0,13 & 0,10 & 6,94 & 7,40 & 0,20 \\
\hline \multicolumn{6}{|c|}{ Ano $2005^{1}$} \\
\hline Janeiro & 0,10 & 0,11 & 10,46 & 7,30 & 0,22 \\
\hline Abril & 0,16 & 0,09 & 10,58 & 9,50 & 0,26 \\
\hline Maio & 0,09 & 0,09 & 5,09 & 10,37 & 0,23 \\
\hline Junho & 0,12 & 0,11 & 10,39 & 10,86 & 0,23 \\
\hline Julho & 0,10 & 0,11 & 3,46 & 9,89 & 0,22 \\
\hline Agosto & 0,10 & 0,11 & 9,52 & 9,49 & 0,24 \\
\hline Setembro & 0,10 & 0,05 & 1,02 & 6,40 & 0,14 \\
\hline Outubro & 0,10 & 0,06 & 14,94 & 3,56 & 0,16 \\
\hline Novembro & 0,12 & 0,09 & 21,22 & 3,43 & 0,17 \\
\hline Dezembro & 0,14 & 0,09 & 7,18 & 5,80 & 0,16 \\
\hline \multicolumn{6}{|c|}{ Ano 2006} \\
\hline Janeiro & 0,14 & 0,08 & 3,34 & 6,12 & 0,13 \\
\hline Fevereiro & 0,10 & 0,06 & 2,16 & 4,45 & 0,12 \\
\hline Março & 0,10 & 0,05 & 3,59 & 5,45 & 0,10 \\
\hline Abril & 0,11 & 0,03 & 2,13 & 3,26 & 0,03 \\
\hline Maio & 0,13 & 0,02 & 3,00 & 2,27 & 0,04 \\
\hline Junho & 0,08 & 0,02 & 2,81 & 1,85 & 0,05 \\
\hline Julho & 0,13 & 0,06 & 3,29 & 6,88 & 0,08 \\
\hline Média Geral $^{2}$ & $\mathbf{0 , 1 1}$ & $\mathbf{0 , 0 8}$ & 7,42 & 6,63 & $\mathbf{0 , 1 7}$ \\
\hline
\end{tabular}

${ }^{1}$ Não foi realizada a análise de tecido de micronutrientes na serapilheira acumulada nos meses fevereiro e março de 2005. ${ }^{2}$ Valores médio referente aos dezenove meses de coleta.

\section{Carbono orgânico na serapilheira acumulada}

Quantidades significativas de nutrientes e carbono orgânico podem retornar ao solo através da queda de componentes senescentes da parte aérea das plantas e sua posterior decomposição. Portanto, a serapilheira é considerada como a principal via de transferência de carbono orgânico para o solo, tornando assim importante a sua quantificação. Cabe ressaltar que raízes; madeira morta; micro, meso e macrofauna também são vias de transferência de carbono orgânico para o solo.

No que se refere ao conteúdo total de carbono orgânico na serapilheira acumulada, a seqüência foi: estádio sucessional II $\left(1,55 \mathrm{Mg} \mathrm{ha}^{-1}\right)>$ estádio sucessional III (1,51 $\left.\mathrm{Mg} \mathrm{ha}^{-1}\right)>$ estádio sucessional I (1,26 Mg ha-1) (Tabela 9).

O valor encontrado de biomassa de carbono orgânico na serapilheira acumulada da presente floresta em estudo não é similar ao valor encontrado por Caldeira (2003) na Floresta Ombrófila Mista Montana (PR), onde o conteúdo de carbono orgânico foi de 3,0 $\mathrm{Mg} \mathrm{ha}^{-1}$. O mesmo pode ser observado no estudo feito por Resende, Merlin e Santos (2001) para a Floresta Alagável, Floresta de Terra Firme e Cerrado, na Ilha do Bananal, TO. A quantidade de carbono orgânico determinado foi de: 3,89; 4,54 e 2,56 $\mathrm{Mg} \mathrm{ha}^{-1}$ respectivamente, na Floresta Alagável, Floresta de Terra Firme e Cerrado. 
Tabela 9. Valores médios do conteúdo de carbono orgânico da serapilheira acumulada nos três estádios sucessionais da Floresta Ombrófila Densa, Blumenau/SC.

\begin{tabular}{lccc}
\hline & \multicolumn{3}{c}{ Carbono orgânico $\left(\mathrm{kg} \mathrm{ha}^{-1}\right) /$ Estádios Sucessionais } \\
\cline { 2 - 4 } & I & II & III \\
\cline { 2 - 4 } & \multicolumn{3}{c}{ Ano 2004} \\
\hline Outubro & 1082,35 & 1540,86 & 1625,39 \\
Novembro & 1104,49 & 1502,90 & 1487,93 \\
Dezembro & 1124,65 & 1872,90 & 1725,03 \\
\hline & \multicolumn{3}{c}{ Ano $2005^{1}$} \\
\hline Janeiro & 940,11 & 1166,14 & 1453,78 \\
Abril & 1064,01 & 1405,37 & 1517,79 \\
Maio & 1056,76 & 1364,04 & 1539,37 \\
Junho & 1041,95 & 1508,73 & 1489,03 \\
Julho & 1089,83 & 1409,84 & 1724,65 \\
Agosto & 921,41 & 1541,15 & 1371,03 \\
Setembro & 2170,14 & 1989,61 & 1504,21 \\
Outubro & 2068,11 & 1708,68 & 1709,27 \\
Novembro & 1802,73 & 1931,77 & 1746,58 \\
Dezembro & 1972,32 & 1735,27 & 2016,66 \\
\hline & & & 1110,63 \\
\hline Janeiro & Ano 2006 & 1185,64 \\
Fevereiro & 1016,81 & 1501,34 & 1419,78 \\
Março & 459,51 & 1626,67 & 1694,12 \\
Abril & 1149,69 & 1452,87 & 1505,01 \\
Maio & 1211,09 & 1701,74 & 1139,36 \\
Junho & 1646,40 & 1574,94 & 1375,02 \\
Julho & 1189,76 & 1297,53 & $\mathbf{1 5 1 7 , 0 1}$ \\
\hline Média Geral & 1137,71 & 1262,81 & \\
\hline
\end{tabular}

${ }^{1}$ Não foi realizada a análise de tecido de carbono orgânico na serapilheira acumulada nos meses fevereiro e março de 2005. ${ }^{2}$ Valor médio referente aos vinte meses de coleta.

Em um estudo realizado por Watzlawick et al. (2002) na Floresta Ombrófila Mista Montana, em General Carneiro (PR) constatou-se não existir diferença marcante na quantidade de carbono na serapilheira acumulada entre os diferentes estádios sucessionais, possuindo 2,99; 3,30 e 2,90 $\mathrm{Mg} \mathrm{ha}^{-1}$ respectivamente no estágio inicial, intermediário e avançado na floresta. Portanto, a queda de folhas e galhos, é um processo fisiológico complexo influenciado por fatores internos e externos como luz, umidade, temperatura, vento, fatores edáficos, poluentes atmosféricos, insetos, doenças, competição entre folhas novas e velhas, fator genético, geadas e em função da disponibilidade de água (KOZLOWSKI; PALLARDY, 1996).

\section{Conclusão}

A produção média de serapilheira acumulada durante o período observado foi de 5,28 $\mathrm{Mg} \mathrm{ha}^{-1}$ (estádio sucessional III); 5,02 $\mathrm{Mg} \mathrm{ha}^{-1}$ (estádio sucessional II) e 4,47 $\mathrm{Mg} \mathrm{ha}^{-1}$ (estádio sucessional I).

Independente do estádio sucessional, as maiores quantidades de serapilheira acumulada ocorreram no verão.

Os maiores teores de $\mathrm{N}$ e $\mathrm{S}$ foram no estádio sucessional III; os de Ca no estádio sucessional II e os de P, K e Mg no estádio sucessional I.

A serapilheira acumulada no estádio sucessional III apresentou os maiores teores de B; no estádio sucessional II os de Cu e Mn e no estádio sucessional I os de Fe e Zn. 
Em ordem decrescente o conteúdo total de macronutrientes na serapilheira acumulada no estádio sucessional I e II foram: $\mathrm{N}>\mathrm{Ca}>\mathrm{Mg}>\mathrm{K}>\mathrm{S}>\mathrm{P}$, no estádio sucessional III: $\mathrm{N}>\mathrm{Ca}>\mathrm{Mg}>\mathrm{S}>\mathrm{K}>\mathrm{P}$.

O conteúdo total de micronutrientes na serapilheira acumulada nos três estádios sucessionais apresentou a seguinte ordem decrescente $\mathrm{Fe}>\mathrm{Mn}>\mathrm{Zn}>\mathrm{B}>\mathrm{Cu}$.

A floresta em estudo apresentou para o conteúdo total de carbono orgânico na serapilheira acumulada, a seguinte seqüência: estádio sucessional II $(1,55 \mathrm{Mg}$ ha $\left.{ }^{-1}\right)>$ estádio sucessional III $\left(1,51 \mathrm{Mg} \mathrm{ha}^{-1}\right)>$ estádio sucessional I (1,26 $\left.\mathrm{Mg} \mathrm{ha}^{-1}\right)$.

\section{Agradecimentos}

Os autores agradecem ao PIBIC/CNPq/FURB pela bolsa de iniciação científica (2004 a 2006), bem como, o prof ${ }^{\circ}$ Moacir Marcolin DEF/CCT/FURB, pelo auxílio nas análises estatísticas.

\section{Referências}

ANDERSON, J. M.; SWIFT, M. J. Decomposition in tropical forests. In: SUTTON, S. L.; WHITMORE, T. C.; CHADWICK, A.C. (Ed.) Tropical rain forest: ecology and management. London: Blackwell Scientific, 1983. p. 287309.

BROWN, P. H.; HU, H. Manejo do boro de acordo com sua mobilidade nas diferentes culturas. Potafos: informações agronômicas, Piracicaba, n. 84, p. 1-4, 1998.

BRUN, E. J.; SCHUMACHER, M. V.; VACCARO, S. Produção de serapilheira e devolução de nutrientes em três fases sucessionais de uma floresta estacional decidual no município de Santa Tereza, RS. In: SIMPÓSIO SOBRE FERTILIZAÇÃO E NUTRIÇÃO FLORESTAL, 1999, Piracicaba. Anais... Piracicaba: ESALQ/USP, 1999. p. 348368. CD-ROM.

BRUN, E. J. SCHUMACHER, M. V. ; VACCARO, S.; LONGHI, S. J.; KOENIG, F. G.; VARGAS, C. O. Decomposição da serapilheira produzida em três fases sucessionais de floresta estacional decidual no RS. In: SIMPÓSIO DE PÓS-GRADUAÇÃO EM ENGENHARIA FLORESTAL, 1., 2001. Anais... Santa Maria: UFSM, 2001. CDROM.
CALDEIRA, M. V. W. Determinação de biomassa e nutrientes em uma Floresta Ombrófila Mista Montana em General Carneiro, Paraná. 2003. Tese (Doutorado em Ciências Florestais) - Setor de Ciências Agrárias da Universidade Federal do Paraná, Curitiba.

CUNHA, G. C. Aspectos da ciclagem de nutrientes em diferentes fases sucessionais de uma Floresta Estacional do Rio Grande do Sul. 1997. Dissertação (Mestrado em Ciências Florestais) - Escola Superior de Agricultura Luiz de Queiroz, Universidade de São Paulo, Piracicaba.

DECHEN, A. R.; NACHTIGALL, G. R. Micronutrientes. In. FERNANDES, M. S. (Ed). Nutrição mineral de plantas. Viçosa: Sociedades Brasileiras de Ciência do Solo, 2006. p. 327-374.

DELITTI, W. B. C. Aspectos comparativos da ciclagem de nutrientes minerais ma mata ciliar, no campo de cerrado e na floresta implantada de Pinus elliottii Engelm. var. elliottii (Mogi-Guaçu, S.P.). 1984. Tese (Doutorado em Ciências) - Instituto de Biociências da Universidade de São Paulo, São Paulo.

EMPRESA BRASILEIRA DE PESQUISA AGROPECUÁRIA - EMBRAPA. Centro Nacional de Pesquisa de Solos. Sistema brasileiro de classificação de solos. Rio de Janeiro: Embrapa Solos, 1999.

FLOSS, P. A.; CALDATO, S. L.; BOHNER, J. A. M. Produção e decomposição de serapilheira na Floresta Ombrófila Mista da reserva florestal da Epagri/Embrapa de Caçador, SC. Revista Agropecuária Catarinense, Florianópolis, v. 12, n. 2, p. 19-22, 1999.

GRUSAK, M. A.; POMPER, K. W. Influence of pod stomatal density and pod transpiration on the calcium concentrations of snap bean pods. Journal American Society Horticulture Science, New York, v. 124, n. 2, p. 194-198, 1999.

HEENAN, J. L.; CAMPBELL, L. C. Transport and distribution of manganese in two cultivars of soybean (Glycine max (L.) Merr.). Australian journal of agricultural research, Melbourne, v. 31, n. 5, p. 943-949, 1980.

JONES JÚNIOR, J. B. Distribution if 15 elements in corn leaves. Communications in Soil Science and Plant Analysis, New York, v. 1, n.1, p. 27-34, 1970.

JORDAN, C. F. Nutrient cycling in tropical forest ecosystems. New York: John Wile, 1985.

KLEIN, R. M. Ecologia da flora e vegetação do vale do Itajaí. Sellowia, Itajaí, v. 32, n. 32, p. 165-389, 1980.

KOZLOWSKI, T. T.; PALLARDY, S. G. Physiological of woody. 2.ed. San Diego: Academic, 1996. 
MALAVOLTA, E. Manual de nutrição de plantas. São Paulo: Agronômica Ceres, 2006.

MARSCHNER, H. Mineral nutrition of higher pants. 2. ed. San Diego: Academic, 1997.

MIYAZAWA, M.; PAVAN, M. A.; MURAOKA, T.; CARMO, C. A. F. S.; MELLO, W. J. Análises químicas de tecido vegetal. In: SILVA, F. C. (Ed). Manual de análises químicas de solos, plantas e fertilizantes. Brasília: Embrapa Solos, 1999. p. 171-223.

MORELLATO, L. P. C. Nutrient cycling in two south-east Brasilian forest. I Litterfall and litter standing crop. Journal of Tropical Ecology, Cambridge, v. 8, n. 1, p. 205-215, 1992.

NEVES, J. C. L. Produção e participação de biomassa, aspectos nutricionais e hídricos em plantios clonais de eucalipto na região litorânea do Espírito Santo. 2000. Tese (Doutorado em Produção Vegetal) - Universidade Estadual do Norte Fluminense, Rio de Janeiro.

NILSSON, L. O.; HÜTTL R. F.; JOHANSSON, U. T.; JOCHHEIM, H. Nutrient uptake and cycling in forest ecosystems - present status and future research directions. Plant and Soil, The Hague, v. 168/169, n. 1, p. 5-13, 1995.

O'CONNELL, A. M.; SANKARAN, K. V. Organic matter accretion, decomposition and mineralisation. In: NAMBIAR, E. K. S., BROWN, A. G. (Ed.) Management of soil, nutrients and water in tropical plantations forests. Canberra: ACIAR Australia/CSIRO, 1997. p. 443-480. (Monograph; n.43).

PAGANO, S. N.; DURIGAN, G. Aspectos da ciclagem de nutrientes em matas ciliares do oeste do estado de São Paulo, Brasil. In: RODRIGUES, R. R; LEITÃO FILHO, H. F. (Ed). Matas ciliares: conservação e recuperação. São Paulo: EDUSP:FAPESP, 2000. p.109-123.

PROCTOR, J. Tropical forest litterfall. I. Problems of data comparison. In: SUTTON, S. L.; WHITMORE, T. C.; CHADWICK (Ed.) Tropical rain forest: ecology and management. Oxford: Blackwell Scientific Publications, 1983. v. 2, p. 267-273.

RESENDE, D.; MERLIN, S.; SANTOS, M. Seqüestro de carbono: uma experiência concreta. 2. ed. Palmas: Instituto Ecologia, 2001.

RODERJAN, C. V.; GALVÃO, F.; KUNYOSHI, Y. S. HATSCHBACH, G. G. As Unidades Fitogeográficas do Estado do Paraná. Ciência \& Ambiente, Santa Maria, v. 24, n. 1, p. 75-92, 2002.

RODERJAN, C. V.; KUNYOSHI, Y. S. Macrozoneamento florístico da área de proteção ambiental - APA de Guaraqueçaba. Curitiba: FUPEF, 1988. (Série Técnica, n. 15)
RODRÍGUEZ JIMÉNEZ, L. V. A. Consideraciones sobre la biomasa, composición química y dinámica del bosque pluvial tropical de colinas bajas. Bajo Calima Buenaventura, Colombia. Bogotá, 1988 . (Serie Corporación Nacional de Investigación y Fomento Forestal, n. 16)

SANTA CATARINA. Gabinete de Planejamento do Estado de Santa Catarina-GAPLAN/SC. Atlas de Santa Catarina. Rio de Janeiro: Aerofoto Cruzeiro, 1986.

SANTOS, G. F. Vale do Garcia (Blumenau-SC): Análise climatogeomorfológica e a repercussão dos episódios pluviais no espaço urbano. 1996. Tese (Doutorado em Geologia) - Universidade de São Paulo, São Paulo.

SCHORN, L. A. Estrutura e dinâmica de estágios sucessionais de uma Floresta Ombrófila Densa em Blumenau, Santa Catarina. 2005. Tese (Doutorado em Ciências Florestais) - Setor de Ciências Agrárias da Universidade Federal do Paraná, Curitiba.

SCHORN, L. A.; GALVÃO, F. Dinâmica da regeneração natural em três estágios sucessionais de uma Floresta Ombrófila Densa em Blumenau, SC. Floresta, Curitiba, v. 36, n. 1, p. 59-74, 2006.

SCHUMACHER, M. V.; CALDEIRA, M. V. W. ; SPATHELF, P.; CAPRA, A. Quantifizierung der biomasse und des nährstoffgehalts bei der erstdurch-forstung eines araukarienbestandes in Quedas do Iguaçu (Paraná, Brasilien). Forstarchiv, Hannover, v. 73, n. 5, p. 187-194, 2002.

TANNER, E. V. J. Litterfall in montane rainforests of Jamaica and its relation to climate. The Journal of Ecology, Oxford, v. 68, n. 3 , p. $833-848,1980$.

TEDESCO, M. J.; GIANELLO, C.; BISSANI, C. A.;BOHNEN, H.; VOLKWEISS, S. J. Análise de solos, plantas e outros materiais. Porto Alegre: UFRG, Departamento de Solos/ Faculdade de Agronomia, 1995. (Boletim Técnico, n. 5).

WATZLAWICK, L. F.; KIRCHNER, F. F.; SANQUETTA, C. R.; SCHUMACHER, M. V. Fixação de carbono em Floresta Ombrófila Mista em diferentes estágios sucessionais. In: SANQUETTA, C. R. WATZLAWICK, L. F.; BALBINOT, R. M.; ZILIOTTO, M. A. B.; GOMES, F. S. (Ed.) As florestas e o carbono. Curitiba: Ed. da UFPR, 2002. p. 153-173.

WEDDERBURN, M. E.; CARTER, J. Litter decomposition by four functional tree types for use in silvopastoral systems. Soil Biology and Biochemistry, Elmsford, v. 31, n. 1, p. 455-461, 1999.

YAMADA, T. Boro: será que estamos aplicando a dose suficiente para o adequado desenvolvimento das planta? Potafos: Informações agronômicas, Piracicaba, n. 90, p. 1$5,2000$. 